\title{
Kerontokan Bunga dan Polong Tiga Varietas Kedelai pada Pemberian Urin Sapi dan Kambing
}

\author{
(Flower and Pods Abscission on Three Soybean Varieties on Cow and Goat Urine Application)
}

\author{
${\text { Fahri } \text { Ali }^{1 *}, \text { Sakhidin }^{1} \text { dan Darjanto }}^{2}$
}

\begin{abstract}
${ }^{1}$ Program Studi Teknologi Produksi Tanaman Hortikultura, Jurusan Budidaya Tanaman Pangan, Politeknik Negeri Lampung ${ }^{2}$ Program Studi Agroteknologi, Fakultas Pertanian, Universitas Jenderal Soedirman Purwokerto *Email Korespondensi: fahrialiagro@gmail.com
\end{abstract}

Diterima 25 Juni 2019 / Disetujui 08 Juli 2019

\begin{abstract}
Problems are often found in soybean plants is the high level of flower and pods abscission. Flower and pods abscission can be caused by various factors such as high concentration of ethylene and low auxin and GA. Cow urine contains a lot of auxin, while goat urine a lot of GA. The aims of the research was to study effect of urine application on flower and pods abscission of soybean varieties. The experiment arranged using Randomized Completelly Block Design, consist of 2 factors, first factor was soybean varieties: Panderman, Burangrang and Anjasmoro. Second factor was urine application: without urine, concentration of cow urine (30 and $\left.60 \mathrm{ml} . \mathrm{l}^{-1}\right)$, concentration of goat urine (30 and $\left.60 \mathrm{ml} . \mathrm{l}^{-1}\right)$. Data were analyzed with $F$ test, and were continuid with DMRT test at 5 percent and correlation analysis when significant. Results showed that urine application affected on the number and percentage of flower abscission. The percentage of flower abscission on Panderman variety decreased with cow or goat urine application, while on Burangrang variety, just cow urine application decreased the percentage of flower abscission. On Anjasmoro variety, cow or goat urine application not decreased the percentage of flower abscission. The highest decreased of the percentage flower abscission on Panderman and Burangrang varieties were cow urine application with concentration of $30 \mathrm{ml.l}^{-1}$, each were $7.90 \%$ and $6.24 \%$. The seed yield (ton.ha ${ }^{-1}$ ), on Panderman variety

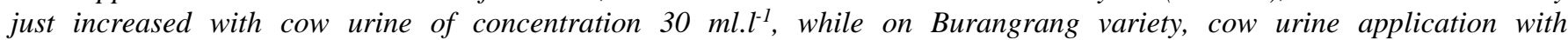
concentration of 30 or $60 \mathrm{ml.l} \mathrm{l}^{-1}$ increased seed yield (ton.ha $\mathrm{a}^{-1}$ ). On Anjasmoro variety, goat urine application with concentration of $30 \mathrm{or} 60 \mathrm{ml.l^{-1 }}$ increased seed yield (ton. $\left.\mathrm{ha}^{-1}\right)$.
\end{abstract}

Keywords: soybean, abscission, urine

\section{ABSTRAK}

Permasalahan yang sering dijumpai pada tanaman kedelai adalah tingginya tingkat kerontokan bunga dan polong. Kerontokan bunga dan polong dapat disebabkan oleh berbagai faktor diantaranya adalah tingginya kandungan etilen dan rendahnya kandungan auksin dan GA. Urin sapi banyak mengandung hormon auksin, sedangkan urin kambing banyak mengandung GA. Penelitian ini bertujuan untuk mengkaji pengaruh pemberian urin terhadap kerontokan bunga dan polong beberapa varietas kedelai. Penelitian ini menggunakan Rancangan Acak Kelompok Lengkap (RAKL), terdiri dari 2 faktor, faktor pertama varietas kedelai : Panderman, Burangrang dan Anjasmoro. Faktor kedua pemberian urin : tanpa urin, urin sapi konsentrasi $30 \mathrm{ml} / \mathrm{l}$; $60 \mathrm{ml} / \mathrm{l}$, urin kambing konsentrasi $30 \mathrm{ml} / \mathrm{l} ; 60 \mathrm{ml} / \mathrm{l}$. Data yang diperoleh dianalisis dengan menggunakan uji $F$, jika nyata dilanjutkan dengan DMRT pada taraf 5\% dan analisis korelasi. Hasil penelitian menunjukkan bahwa pemberian urin berpengaruh terhadap jumlah bunga rontok dan persentase bunga rontok. Persentase bunga rontok pada varietas Panderman dapat dikurangi dengan pemberian urin sapi maupun kambing, sedangkan pada varietas Burangrang dapat dikurangi hanya dengan pemberian urin sapi. Pada varietas Anjasmoro pemberian urin baik sapi maupun kambing tidak dapat mengurangi persentase bunga rontok. Penurunan persentase bunga rontok tertinggi pada varietas Panderman dan Burangrang diperoleh dengan pemberian urin sapi konsentrasi $30 \mathrm{ml} / \mathrm{l}$ yaitu masing-masing sebesar 7,90\% dan 6,24\%. Bobot biji per hektar pada varietas Panderman dapat meningkat hanya dengan pemberian urin sapi konsentrasi $30 \mathrm{ml} / \mathrm{l}$. Pada varietas Burangrang dapat meningkat dengan pemberian urin sapi baik konsentrasi 30 atau $60 \mathrm{ml} / \mathrm{l}$. Pada varietas Anjasmoro dapat meningkat dengan pemberian urin kambing baik konsentrasi 30 atau $60 \mathrm{ml} / \mathrm{l}$.

Kata kunci: kedelai, kerontokan, urin 


\section{PENDAHULUAN}

Permasalahan yang sering dijumpai pada tanaman kedelai adalah tingginya tingkat kerontokan bunga dan polong. Berdasarkan hasil penelitian Suyamto dan Musalamah (2010) dari 20 varietas kedelai di Indonesia yang diteliti, 15 varietas diantaranya mempunyai tingkat kerontokan bunga yang tinggi yaitu berkisar antara 21-39\%. Umumnya kedelai mempunyai jumlah bunga dan polong awal yang banyak, namun pada akhirnya bunga maupun polong awal akan mengalami kerontokan. Carlson dan Lersten (1978) menyatakan bahwa aborsi ovul terjadi pada awal perkembangan embrio, yaitu 3-7 hari setelah pembungaan.

Kerontokan bunga dan buah (polong) dapat disebabkan oleh berbagai faktor diantaranya adalah tingginya kandungan etilen dan rendahnya kandungan auksin dan GA (Aneja et al., 1999). Auksin merupakan hormon yang berperan dalam mencegah absisi, sedangkan giberelin dapat meningkatkan kandungan auksin pada bunga sehingga mencegah terjadinya absisi bunga (Gardner et al., 1991). Cho et al. (2002) melaporkan bahwa pemberian 2,4DP pada konsentrasi rendah $(0,04 \mathrm{mM})$ dapat mengurangi bunga rontok pada kedelai, sedangkan pada konsentrasi tinggi $(0,12 \mathrm{mM})$ tidak dapat mengurangi bunga rontok. ElSaeid et al. (2010) juga melaporkan bahwa pemberian IAA dengan konsentrasi $25 \mathrm{mg} / \mathrm{l}$ dan $50 \mathrm{mg} / \mathrm{l}$ dapat mengurangi tingkat kerontokan bunga pada kacang tunggak.

Urin ternak ruminansia merupakan bahan yang mengandung berbagai jenis hormon. Prawoto dan Suprijadji (1992) melaporkan ada dua jenis hormon penting yang dikandung urin ternak ruminansia yaitu auksin dan asam giberelin (GA). Urin sapi merupakan jenis urin yang banyak mengandung auksin, sedangkan urin kambing banyak mengandung giberelin. Kadar auksin urin sapi rata-rata 783 ppm, sedangkan kadar giberelin urin kambing rata-rata 821 ppm.

Kadar auksin dan giberelin tertinggi diperoleh setelah dilakukan fermentasi selama 5 hari. Penelitian ini bertujuan untuk menentukkan pengaruh pemberian urin sapi maupun kambing terhadap tingkat kerontokan bunga dan polong tiga varietas kedelai, dan menentukkan pengaruh interaksi antara varietas kedelai dengan pemberian urin terhadap tingkat kerontokan bunga dan polong.

\section{BAHAN DAN METODE}

Bahan yang digunakan dalam penelitian ini meliputi lahan pertanian tadah hujan dengan jenis tanah Ultisol, varietas kedelai Panderman, Burangrang dan Anjasmoro, urin sapi, urin kambing, pupuk Urea, SP-18, KCl, kapur pertanian (Dolomit), pupuk kandang sapi dan perekat. Peralatan yang digunakan antara lain : cangkul, timbangan, hand sprayer, roll meter, gelas ukur dan seed moisture tester.

Penelitian ini telah dilaksanakan di lahan desa Pucungbedug, Kecamatan Purwanegara, Kabupaten Banjarnegara, dengan ketinggian tempat $240 \mathrm{~m}$ dpl. Penelitian ini merupakan percobaan faktorial 3 x 5 dengan menggunakan rancangan lingkungan acak kelompok lengkap (RAKL) dengan tiga ulangan. Faktor yang dicoba yaitu varietas kedelai dan pemberian urin. Varietas kedelai terdiri dari : Panderman, Burangrang dan Anjasmoro. Pemberian urin terdiri dari : tanpa pemberian urin, pemberian urin sapi konsentrasi $30 \mathrm{ml} / \mathrm{l}$, pemberian urin sapi konsentrasi $60 \mathrm{ml} / \mathrm{l}$, pemberian urin kambing konsentrasi 30 $\mathrm{ml} / \mathrm{l}$ dan pemberian urin kambing konsentrasi $60 \mathrm{ml} / \mathrm{l}$. Kombinasi perlakuan yang diperoleh sebanyak 15 kombinasi perlakuan, sehingga unit percobaan keseluruhan berjumlah 45 unit percobaan.

Pemberian urin sapi dan kambing dilakukan dengan cara disemprotkan pada daun bagian bawah dengan konsentrasi sesuai dengan perlakuan dan dicampur dengan perekat. Penyemprotan urin dilakukan 3 kali, yaitu pada umur 3, 4 dan 5 minggu setelah tanam (mst). Urin yang digunakan merupakan urin yang telah difermentasi selama 5 hari.

Variabel yang diamati yaitu umur berbunga, jumlah bunga, jumlah bunga rontok, persentase bunga rontok, jumlah polong jadi, jumlah polong panen, jumlah polong rontok, persentase polong rontok, jumlah polong isi, persentase polong isi, jumlah poong hampa, persentase polong hampa, bobot biji per tanaman, bobot 100 biji dan bobot biji per hektar. Data yang diperoleh dianalisis dengan menggunakan uji F. Apabila hasil uji menunjukkan perbedaan yang nyata antar perlakuan maka dilanjutkan dengan $D M R T$ pada $\alpha 5 \%$ dan analisis korelasi.

\section{HASIL DAN PEMBAHASAN}

Tabel 1 menunjukkan pengaruh interaksi antara varietas kedelai dengan pemberian urin terhadap persentase bunga rontok. Pada varietas Panderman, pemberian urin sapi baik konsentrasi 30 maupun $60 \mathrm{ml} / \mathrm{l}$ dapat mengurangi persentase bunga rontok masing-masing sebesar 7,90\% dan $3,08 \%$, sedangkan pemberian urin kambing baik konsentrasi 30 atau $60 \mathrm{ml} / \mathrm{l}$ dapat mengurangi persentase bunga rontok masing-masing sebesar $3,91 \%$ dan $5,6 \%$. Pada varietas Burangrang, hanya pemberian urin sapi yang dapat mengurangi persentase bunga rontok. Penurunan persentase bunga rontok pada pemberian urin sapi baik konsentrasi 30 atau $60 \mathrm{ml} / 1$ masing-masing sebesar 6,24\% dan 4,3\%. Pada varietas Anjasmoro, pemberian urin baik sapi maupun kambing tidak dapat mengurangi persentase bunga rontok, bahkan pemberian urin sapi konsentrasi $60 \mathrm{ml} / \mathrm{l}$ meningkatkan persentase bunga rontok sebesar 2,76\%. Jadi, penurunan persentase bunga rontok tertinggi pada varietas Panderman dan Burangrang diperoleh dengan pemberian urin sapi konsentrasi $30 \mathrm{ml} / \mathrm{l}$ yaitu masing-masing sebesar $7,90 \%$ dan $6,24 \%$.

Pemberian urin sapi dapat mengurangi persentase bunga rontok pada varietas Panderman dan Burangrang diduga karena kedua varietas tersebut mempunyai tingkat kerontokan bunga yang tinggi (Suyamto dan Musalamah, 2010), sehingga responsif terhadap pemberian urin sapi yang mengandung hormon auksin. Menurut Prawoto dan Suprijadji (1992) kadar auksin urin sapi rata-rata 783 ppm. Urin sapi yang diberikan dapat meningkatkan konsentrasi auksin pada zona absisi, sehingga mencegah absisi. 
Perkembangan zona absisi dapat dihambat dengan meningkatnya konsentrasi IAA serta menurunnya etilen dan ABA.

Pemberian urin kambing hanya dapat mengurangi persentase bunga rontok pada varietas Panderman (Tabel 1). Hal tersebut diduga karena hormon giberelin yang terkandung dalam urin kambing (Prawoto dan Suprijadji, 1992) berperan secara tidak langsung meningkatkan kandungan auksin pada bunga sehingga mencegah terjadinya absisi bunga (Gardner et al., 1991).

Pemberian urin sapi dan kambing tidak dapat mengurangi persentase bunga rontok pada varietas Anjasmoro (Tabel 1), diduga karena kandungan auksin endogen pada varietas tersebut sudah cukup tinggi. Hal tersebut dapat dilihat apabila konsentrasi pemberian urin sapi ditingkatkan menjadi $60 \mathrm{ml} / \mathrm{l}$ meningkatkan persentase bunga rontok. Konsentrasi auksin yang terlalu tinggi merangsang pembentukan etilen (Burg, 1973).

Tabel 2, 3 dan 4 menunjukkan pengaruh interaksi antara varietas kedelai dengan pemberian urin terhadap jumlah polong jadi, jumlah polong panen dan jumlah polong isi. Pada varietas Panderman, jumlah polong jadi, jumlah polong panen dan jumlah polong isi dapat meningkat dengan pemberian urin sapi konsentrasi $30 \mathrm{ml} / \mathrm{l}$ atau urin kambing baik konsentrasi 30 maupun $60 \mathrm{ml} / \mathrm{l}$. Pada varietas Burangrang, jumlah polong panen dapat meningkat dengan pemberian urin sapi konsentrasi $60 \mathrm{ml} / \mathrm{l}$. Pada varietas Anjasmoro, jumlah polong jadi, jumlah polong panen dan jumlah polong isi dapat meningkat dengan pemberian urin kambing baik konsentrasi 30 atau $60 \mathrm{ml} / \mathrm{l}$.

Peningkatan jumlah polong jadi, jumlah polong panen dan jumlah polong isi pada varietas Panderman dengan pemberian urin sapi konsentrasi $30 \mathrm{ml} / \mathrm{l}$ diduga berkaitan dengan penurunan persentase bunga rontok. Ada korelasi antara persentase bunga rontok dengan jumlah polong jadi, jumlah polong panen dan jumlah polong isi, dengan nilai korelasi berturut-turut adalah: $r=-0,98, r=-$ 0,99 dan $r=-0,90$. Semakin menurun persentase bunga rontok, maka jumlah polong jadi, jumlah polong panen dan jumlah polong isi semakin meningkat.

Tabel 1. Persentase bunga rontok $(\%)$ beberapa varietas kedelai pada pemberian urin

\begin{tabular}{lcccccc}
\hline \multirow{2}{*}{ Perlakuan } & \multirow{2}{*}{ Kontrol } & \multicolumn{2}{c}{ Urin Sapi } & \multicolumn{2}{c}{ Urin Kambing } & \multirow{2}{*}{ Rerata } \\
\cline { 2 - 6 } & & {$[30 \mathrm{ml} / \mathrm{l}]$} & {$[60 \mathrm{ml} / \mathrm{l}]$} & {$[30 \mathrm{ml} / \mathrm{l}]$} & {$[60 \mathrm{ml} / \mathrm{l}]$} & \\
\hline Panderman & $23,46 \mathrm{c} \mathrm{B}$ & $15,56 \mathrm{a} \mathrm{B}$ & $20,38 \mathrm{~b} \mathrm{C}$ & $19,55 \mathrm{~b} \mathrm{~B}$ & $17,86 \mathrm{ab} \mathrm{B}$ & 19,36 \\
Burangrang & $21,72 \mathrm{~b} \mathrm{~B}$ & $15,48 \mathrm{a} \mathrm{B}$ & $17,42 \mathrm{a} \mathrm{B}$ & $20,07 \mathrm{~b} \mathrm{~B}$ & $21,14 \mathrm{~b} \mathrm{C}$ & 19,17 \\
Anjasmoro & $11,12 \mathrm{a} \mathrm{A}$ & $12,08 \mathrm{ab} \mathrm{A}$ & $13,88 \mathrm{~b} \mathrm{~A}$ & $10,55 \mathrm{a} \mathrm{A}$ & $10,03 \mathrm{a} \mathrm{A}$ & 11,53 \\
\hline Rerata & 18,77 & 14,37 & 17,23 & 16,73 & 16,34 & $(+)$ \\
\hline
\end{tabular}

Keterangan : (+) : terjadi interaksi; angka-angka yang diikuti huruf kecil yang sama pada baris yang sama atau angka-angka yang diikuti huruf besar yang sama pada kolom yang sama menunjukkan tidak berbeda nyata pada uji DMRT $\alpha$ 5\%.

Tabel 2. Jumlah polong jadi (buah) beberapa varietas kedelai pada pemberian urin

\begin{tabular}{cccccccc}
\hline & & \multicolumn{3}{c}{ Urin Sapi } & \multicolumn{4}{c}{ Urin Kambing } \\
\cline { 2 - 6 } Perlakuan & Kontrol & {$[30 \mathrm{ml} / \mathrm{l}]$} & {$[60 \mathrm{ml} / \mathrm{l}]$} & {$[30 \mathrm{ml} / \mathrm{l}]$} & {$[60 \mathrm{ml} / \mathrm{l}]$} & Rerata \\
\hline Panderman & $21,77 \mathrm{a} \mathrm{A}$ & $28,43 \mathrm{~b} \mathrm{~A}$ & $24,90 \mathrm{ab} \mathrm{A}$ & $27,40 \mathrm{~b} \mathrm{~A}$ & $27,63 \mathrm{~b} \mathrm{~A}$ & 26,03 \\
Burangrang & $44,73 \mathrm{ab} \mathrm{B}$ & $48,28 \mathrm{ab} \mathrm{B}$ & $49,37 \mathrm{~b} \mathrm{~B}$ & $44,64 \mathrm{ab} \mathrm{B}$ & $44,30 \mathrm{a} \mathrm{B}$ & 46,26 \\
Anjasmoro & $54,97 \mathrm{a} \mathrm{C}$ & $52,92 \mathrm{a} \mathrm{C}$ & $51,26 \mathrm{a} \mathrm{B}$ & $63,67 \mathrm{~b} \mathrm{C}$ & $63,07 \mathrm{~b} \mathrm{C}$ & 57,18 \\
\hline \multicolumn{1}{c}{ Rerata } & 40,49 & 43,21 & 41,84 & 45,24 & 45,00 & $(+)$ \\
\hline
\end{tabular}

Keterangan : (+) : terjadi interaksi; angka-angka yang diikuti huruf kecil yang sama pada baris yang sama atau angka-angka yang diikuti huruf besar yang sama pada kolom yang sama menunjukkan tidak berbeda nyata pada uji DMRT $\alpha$ $5 \%$.

Tabel 3. Jumlah polong panen (buah) beberapa varietas kedelai pada pemberian urin

\begin{tabular}{ccccccc} 
& & \multicolumn{3}{c}{ Urin Sapi } & \multicolumn{2}{c}{ Urin Kambing } \\
\cline { 2 - 6 } Perlakuan & Kontrol & {$[30 \mathrm{ml} / \mathrm{l}]$} & {$[60 \mathrm{ml} / \mathrm{l}]$} & {$[30 \mathrm{ml} / \mathrm{l}]$} & {$[60 \mathrm{ml} / \mathrm{l}]$} & Rerata \\
\hline Panderman & $18,89 \mathrm{a} \mathrm{A}$ & $25,02 \mathrm{~b} \mathrm{~A}$ & $21,60 \mathrm{ab} \mathrm{A}$ & $23,41 \mathrm{~b} \mathrm{~A}$ & $23,86 \mathrm{~b} \mathrm{~A}$ & 22,55 \\
Burangrang & $40,38 \mathrm{ab} \mathrm{B}$ & $43,80 \mathrm{bc} \mathrm{B}$ & $44,18 \mathrm{c} \mathrm{B}$ & $40,10 \mathrm{a} \mathrm{B}$ & $39,76 \mathrm{a} \mathrm{B}$ & 41,64 \\
Anjasmoro & $49,46 \mathrm{a} \mathrm{C}$ & 47,36 a C & $45,90 \mathrm{a} \mathrm{B}$ & $56,23 \mathrm{~b} \mathrm{C}$ & $55,98 \mathrm{~b} \mathrm{C}$ & 50,99 \\
\hline \multicolumn{1}{c}{ Rerata } & 36,24 & 38,72 & 37,23 & 39,91 & 39,87 & $(+)$ \\
\hline
\end{tabular}

Keterangan : (+) : terjadi interaksi; angka-angka yang diikuti huruf kecil yang sama pada baris yang sama atau angka-angka yang diikuti huruf besar yang sama pada kolom yang sama menunjukkan tidak berbeda nyata pada uji DMRT $\alpha$ $5 \%$. 
Tabel 4. Jumlah polong isi (buah) beberapa varietas kedelai pada pemberian urin

\begin{tabular}{|c|c|c|c|c|c|c|}
\hline \multirow[b]{2}{*}{ Perlakuan } & \multirow[b]{2}{*}{ Kontrol } & \multicolumn{2}{|c|}{ Urin Sapi } & \multicolumn{2}{|c|}{ Urin Kambing } & \multirow[b]{2}{*}{ Rerata } \\
\hline & & {$[30 \mathrm{ml} / \mathrm{l}]$} & {$[60 \mathrm{ml} / \mathrm{l}]$} & {$[30 \mathrm{ml} / \mathrm{l}]$} & {$[60 \mathrm{ml} / \mathrm{l}]$} & \\
\hline Panderman & 16,49 a $\mathrm{A}$ & 22,42 b A & $19,07 \mathrm{ab} A$ & $21,84 \mathrm{~b} \mathrm{~A}$ & $21,92 \mathrm{~b} \mathrm{~A}$ & 20,35 \\
\hline Burangrang & 31,78 abc B & 34,20 bc B & 34,98 с B & $30,96 \mathrm{ab} B$ & 30,30 a B & 32,44 \\
\hline Anjasmoro & 37,12 a $\mathrm{C}$ & 36,69 a $\mathrm{B}$ & 35,34 a $\mathrm{B}$ & $43,90 \mathrm{~b} \mathrm{C}$ & $42,78 \mathrm{~b} \mathrm{C}$ & 39,17 \\
\hline Rerata & 28,47 & 31,10 & 29,80 & 32,23 & 31,67 & $(+)$ \\
\hline
\end{tabular}

Keterangan : (+) : terjadi interaksi; angka-angka yang diikuti huruf kecil yang sama pada baris yang sama atau angka-angka yang diikuti huruf besar yang sama pada kolom yang sama menunjukkan tidak berbeda nyata pada uji DMRT $\alpha$ $5 \%$.

Tabel 5. Bobot biji per tanaman $(\mathrm{g})$ beberapa varietas kedelai pada pemberian urin

\begin{tabular}{|c|c|c|c|c|c|c|}
\hline \multirow[b]{2}{*}{ Perlakuan } & \multirow[b]{2}{*}{ Kontrol } & \multicolumn{2}{|c|}{ Urin Sapi } & \multicolumn{2}{|c|}{ Urin Kambing } & \multirow[b]{2}{*}{ Rerata } \\
\hline & & {$[30 \mathrm{ml} / \mathrm{l}]$} & {$[60 \mathrm{ml} / \mathrm{l}]$} & {$[30 \mathrm{ml} / \mathrm{l}]$} & {$[60 \mathrm{ml} / \mathrm{l}]$} & \\
\hline Panderman & 7,74 a $\mathrm{A}$ & 10,48 b A & $8,73 \mathrm{ab} A$ & $9,78 \mathrm{~b} \mathrm{~A}$ & $9,73 \mathrm{~b} \quad \mathrm{~A}$ & 9,29 \\
\hline Burangrang & 11,95 a $\mathrm{B}$ & 13,94 b B & 14,63 b C & 11,62 a B & 11,54 a $B$ & 12,74 \\
\hline Anjasmoro & $12,77 \mathrm{ab} B$ & 11,41 a $\mathrm{A}$ & 11,84 a B & $15,28 \mathrm{c} \mathrm{C}$ & $14,18 \mathrm{bc} \mathrm{C}$ & 13,10 \\
\hline Rerata & 10,82 & 11,94 & 11,73 & 12,23 & 11,82 & $(+)$ \\
\hline
\end{tabular}

Keterangan : (+) : terjadi interaksi; angka-angka yang diikuti huruf kecil yang sama pada baris yang sama atau angka-angka yang diikuti huruf besar yang sama pada kolom yang sama menunjukkan tidak berbeda nyata pada uji DMRT $\alpha$ $5 \%$.

Tabel 6. bobot biji per hektar (ton/ha) beberapa varietas kedelai pada pemberian urin

\begin{tabular}{|c|c|c|c|c|c|c|}
\hline \multirow[b]{2}{*}{ Perlakuan } & \multirow[b]{2}{*}{ Kontrol } & \multicolumn{2}{|c|}{ Urin Sapi } & \multicolumn{2}{|c|}{ Urin Kambing } & \multirow[b]{2}{*}{ Rerata } \\
\hline & & {$[30 \mathrm{ml} / \mathrm{l}]$} & {$[60 \mathrm{ml} / \mathrm{l}]$} & {$[30 \mathrm{ml} / \mathrm{l}]$} & {$[60 \mathrm{ml} / \mathrm{l}]$} & \\
\hline Panderman & 1,56 a $A$ & $1,96 \mathrm{~b} \mathrm{~A}$ & $1,64 \mathrm{ab} \mathrm{A}$ & $1,83 \mathrm{ab} \mathrm{A}$ & $1,82 \mathrm{ab} \mathrm{A}$ & 1,76 \\
\hline Burangrang & 1,99 а B & $2,28 \mathrm{~b} \mathrm{~B}$ & 2,39 b C & 1,94 a A & 1,92 a $A$ & 2,10 \\
\hline Anjasmoro & 1,91 a B & 1,78 a $\mathrm{A}$ & 1,85 a B & $2,39 \mathrm{~b} \quad \mathrm{~B}$ & $2,22 \mathrm{~b} \quad \mathrm{~B}$ & 2,03 \\
\hline Rerata & 1,82 & 2,01 & 1,96 & 2,05 & 1,99 & $(+)$ \\
\hline
\end{tabular}

Keterangan : (+) : terjadi interaksi; angka-angka yang diikuti huruf kecil yang sama pada baris yang sama atau angka-angka yang diikuti huruf besar yang sama pada kolom yang sama menunjukkan tidak berbeda nyata pada uji DMRT $\alpha$ $5 \%$.

Pemberian urin kambing dapat meningkatkan jumlah polong jadi, jumlah polong panen dan jumlah polong isi pada varietas Panderman dan Anjasmoro (Tabel 2, 3 dan 4). Hal tersebut diduga karena hormon giberelin yang terkandung dalam urin kambing. Menurut Prawoto dan Suprijadji (1992), kadar giberelin urin kambing rata-rata 821 ppm. Giberelin bekerja secara sinergis dengan auksin untuk mempengaruhi peningkatan fruitset dan pembebasan enzim $\alpha$-amilase untuk menghidrolisis tepung manjadi gula yang dibutuhkan untuk pertumbuhan dan perkembangan polong (Gardner et al., 1991).

Tabel 5 menunjukkan pengaruh interaksi antara varietas kedelai dengan pemberian urin terhadap bobot biji per tanaman. Pada varietas Panderman, bobot biji per tanaman dapat meningkat dengan pemberian urin sapi konsentrasi $30 \mathrm{ml} / \mathrm{l}$ atau urin kambing baik konsentrasi 30 maupun $60 \mathrm{ml} / \mathrm{l}$. Pada varietas Burangrang, dapat meningkat dengan pemberian urin sapi baik konsentrasi 30 atau $60 \mathrm{ml} / \mathrm{l}$. Pada varietas Anjasmoro, dapat meningkat hanya dengan pemberian urin kambing konsentrasi $30 \mathrm{ml} / \mathrm{l}$.

Peningkatan bobot biji per tanaman pada varietas Panderman dan Burangrang oleh perlakuan pemberian urin sapi konsentrasi $30 \mathrm{ml} / \mathrm{l}$ diduga berkaitan dengan peningkatan jumlah polong jadi, jumlah polong panen dan jumlah polong isi. Ada korelasi antara jumlah polong jadi, jumlah polong panen dan jumlah polong isi dengan bobot biji per tanaman, dengan nilai korelasi berturut-turut adalah: $r=0,83, r=0,76$ dan $r=0,93$ untuk varietas Panderman, sedangkan $r=0,96, r=0,97$ dan $r=0,97$ untuk varietas Burangrang. Semakin meningkat jumlah polong jadi, jumlah polong panen dan jumlah polong isi, maka bobot biji per tanaman semakin meningkat. Menurut Musa (1978), bobot biji per tanaman mempunyai hubungan yang erat dengan komponen hasil yang meliputi jumlah polong total per tanaman dan ukuran biji.

Pemberian urin kambing dapat meningkatkan bobot biji per tanaman pada varietas Panderman (Tabel 5). Hal tersebut diduga berkaitan dengan peningkatan jumlah polong jadi, jumlah polong panen dan jumlah polong isi. Ada korelasi antara jumlah polong jadi, jumlah polong panen dan jumlah polong isi dengan bobot biji per tanaman, dengan nilai korelasi yang sama yaitu: $r=0,99$. Arsyad dan Asadi (1998) menyatakan jumlah polong yang banyak merupakan sifat komponen hasil sebagai penunjang diperolehnya hasil tanaman yang tinggi. 
Pemberian urin kambing konsentrasi $30 \mathrm{ml} / \mathrm{l}$ dapat meningkatkan bobot biji per tanaman pada varietas Anjasmoro (Tabel 5). Hal tersebut diduga berkaitan dengan peningkatan jumlah polong jadi, jumlah polong panen dan jumlah polong isi. Ada korelasi antara jumlah polong jadi, jumlah polong panen dan jumlah polong isi dengan bobot biji per tanaman, dengan nilai korelasi berturut-turut adalah: $r=0,60, r=0,69$ dan $r=0,82$.

Tabel 6 menunjukkan pengaruh interaksi antara varietas kedelai dengan pemberian urin terhadap bobot biji per hektar. Pada varietas Panderman, bobot biji per hektar dapat meningkat hanya dengan pemberian urin sapi konsentrasi $30 \mathrm{ml} / \mathrm{l}$. Pada varietas Burangrang, dapat meningkat dengan pemberian urin sapi baik konsentrasi 30 atau $60 \mathrm{ml} / \mathrm{l}$. Pada varietas Anjasmoro, dapat meningkat dengan pemberian urin kambing baik konsentrasi 30 atau 60 $\mathrm{ml} / \mathrm{l}$.

Peningkatan bobot biji per hektar pada varietas Panderman dan Burangrang dengan pemberian urin sapi konsentrasi $30 \mathrm{ml} / \mathrm{l}$ diduga berkaitan dengan peningkatan jumlah polong jadi, jumlah polong panen dan jumlah polong isi. Ada korelasi antara jumlah polong jadi, jumlah polong panen dan jumlah polong isi dengan bobot biji per hektar, dengan nilai korelasi berturut-turut adalah: $r=0,82, r=0,76$ dan $r=0,93$ untuk varietas Panderman, sedangkan $r=0,96, r$ $=0,97$ dan $r=96$ untuk varietas Burangrang. Suwarto dan Farid (1991) menyatakan terdapat korelasi positif antara jumlah polong per tanaman dengan hasil biji.

Pemberian urin kambing dapat meningkatkan bobot biji per hektar pada varietas Anjasmoro (Tabel 6). Hal tersebut diduga berkaitan dengan peningkatan jumlah polong jadi, jumlah polong panen dan jumlah polong isi. Ada korelasi antara jumlah polong jadi, jumlah polong panen dan jumlah polong isi dengan bobot biji per hektar, dengan nilai korelasi berturut-turut adalah: $r=0,60, r=0,70$ dan 0,82 untuk pemberian urin kambing konsentrasi $30 \mathrm{ml} / \mathrm{l}$, sedangkan untuk pemberian urin sapi konsentrasi $60 \mathrm{ml} / \mathrm{l}$ nilai korelasi sama yaitu: $\mathrm{r}=0,99$. Rogers et al. (1984) menyatakan hasil biji biasanya berhubungan erat dengan jumlah polong isi.

\section{KESIMPULAN}

Pemberian urin berpengaruh terhadap jumlah bunga rontok dan persentase bunga rontok. Persentase bunga rontok pada varietas Panderman dapat dikurangi dengan pemberian urin sapi maupun kambing, sedangkan pada varietas Burangrang dapat dikurangi hanya dengan pemberian urin sapi. Pada varietas Anjasmoro pemberian urin baik sapi maupun kambing tidak dapat mengurangi persentase bunga rontok. Penurunan persentase bunga rontok tertinggi pada varietas Panderman dan Burangrang diperoleh dengan pemberian urin sapi konsentrasi $30 \mathrm{ml} / \mathrm{l}$ yaitu masing-masing sebesar 7,90\% dan $6,24 \%$.

\section{DAFTAR PUSTAKA}

Aneja, M. dan T. Gianfagna. 1999. The Role of Absisic Acid and Ethylene in the Abscission and Senescence of Cocoa Flower. Plant Growth Regulation. 27:149155.

Arsyad, D.M. dan Asadi. 1998. Pemanfaatan Plasma Nutfah Kedelai untuk Program Pemuliaan. Makalah. Komisi Nasional Plasma Nutfah, Departeman Pertanian. 25 hal.

Burg, S.P. 1973. Ethylene in Plant Growth. Proc. Nat. Acad. Sci. USA. 70(2):591-597.

Carlson, J.B. dan N.R. Lersten. 1978. Reproductive Morfology. In J.R. Wilcox (ed.) Soybean, Improvements, Production and Uses. USA. Medison. pp. 234-278.

Cho, Y., S.K. Suh, H.K. Park dan A. Wood. 2002. Impact of 2,4-DP and BAP Upon Pod Set and Seed Yield in Soybean Treated at Reproduktive stages. Plant Growth Regulation. 36:215-221.

El-Saeid, H.M., S.D.A. Hussein dan W.A. El-Tohamy. 2010. Growth Characters, Yield and Endogenous Hormons of Cowpea Plants in Response to IAA Aplication. Agriculture and Biological Sciences. 6(1):27-31.

Gardner, F.P., R.B Pearce dan R.L. Mitchell. 1991. Fisiologi Tanaman Budidaya. Universitas Indonesia, Jakarta. 428 hal.

Musa, S. 1978. Beberapa Hasil Evaluasi Terhadap Bahan Genetik Kedelai Yang Diuji Di Kebun Percobaan Cikarawang. Kanisius, Yogyakarta. 96 hal.

Prawoto, A.A. dan G. Suprijadji. 1992. Kandungan Hormon dalam Air Seni Beberapa Jenis Ternak. Pelita Perkebunan. 7(4):79-84.

Rogers, H.H., J.D. Cure, J.F. Thomas dan J.M. Smith. 1984. Influence of elevated carbon dioxide on growth of soybean plants. Crop Sci. 24:361-366.

Suwarto dan N. Farid. 1991. Evaluasi F-6 Hasil Persilangan Kedelai Varietas Dempo x Wilis. Laporan Hasil Penelitian. Purwokerto (ID): Fakultas Pertanian Unsoed, 32 hal.

Suyamto dan Musalamah. 2010. Kemampuan Berbunga, Tingkat Kerontokan Bunga dan Potensi Hasil Beberapa Varietas Kedelai. Buletin Plasma Nutfah. 16 (1):38-43. 